\title{
New Noises New Voices
}

\author{
Martina Raponi \\ Noiserr \\ martina.raponi@gmail.com / info@noiserr.xyz
}

\begin{abstract}
As an artist interested in Noise, and a CODA (child of deaf adults), I will tackle the issue of noise and counterculture from the entry point of deafness and un-cultured voices. In ableist societies the voice is a cultural product, and certain voices, perceived as "other", flawed, "noisy", can open up discourses related to shared sonic spaces, disruption, and inclusivity. Soundscape is here described as a social and political environment, and the bodies immersed in it are considered according to the entire spectrum of their capacities, beyond listening, in rhythm analytical terms. Soundscape, understood within the thresholds of audibility, expels, and rejects communities which carry the stigma of "handicap", such as Deaf communities. This theoretical exercise is accompanied by examples from contemporary art and technological-historical references, pointing at "acts of silencing" and "acts of noising", while underlining the value of "deviant" bodies as resistant bodies. The paper ends with the testimony of a Deaf dancer who used my writings to produce her last two shows. I will refer to the audiological deaf using the lowercase and capitalize the linguistic minority: Deaf. Despite being considered disabled, or deviant, Deaf bodies are the last example of countercultural agents in all-speaking and all-hearing ableist societies.
\end{abstract}

Keywords: noise, deafness, voice, counterculture, soundscape, vibration.

\section{Novos ruídos, novas vozes}

Como artista interessada em Noise e filha de pais surdos, abordarei a questão do ruído e da contracultura a partir da questão da surdez e das vozes não cultivadas. Nas sociedades de pessoas sem deficiências a voz é um produto cultural e certas vozes percebidas como "outras", imperfeitas, "barulhentas", podem gerar discursos ligados ao compartilhamento de espaços sonoros, perturbações e inclusões. Tomo a paisagem sonora como um ambiente social e político, e os corpos ali imersos são considerados para além da escuta, incorporando o espectro total de suas capacidades, em termos rítmico-analíticos. A paisagem sonora, entendida dentro dos limites da audibilidade, expele e rejeita comunidades que carregam o estigma da "deficiência" como é o caso da comunidade dos surdos. Este exercício teórico é acompanhado por exemplos de arte contemporânea e de referências histórico-tecnológicas, apontando para "atos de silenciamento" e "atos de ruído". Ao mesmo tempo, sublinha o valor de corpos "desviantes" como corpos que resistem. O artigo termina com o testemunho de uma dançarina surda que usou meus textos para produzir seus dois últimos trabalhos. Apesar de serem considerados deficientes ou desviantes, Surdos são um exemplo significativo de agentes contraculturais em sociedades plenamente habilitadas nas capacidades da fala e da escuta.

Palavras-chave: Ruído. Surdez. Voz. Contracultura. Paisagem sonora. Vibração. 


\section{(intro-)SOUND-}

We inhabit sound, because it happens to us. We do not inhabit the world of vision because our acts of looking are constantly doing things to that world. Looking [...] is a kind of having. Listening can only approximate to this appropriative hand-eye coordination (CONNOR, 2011, p. 135).

Sound is immersive, it possesses us, but this doesn't mean that we are fully passive when it happens to us. We do not merely "hear" sound, but we listen instead, we select and isolate signals from random sonic inputs or from background noises. The words of Steve Connor help us set off our argumentations in order to define the particular importance of the aural environment, and the sensory activities and reactions it triggers. Magnifying the aural environment is relevant here because on the one hand it is the realm of sharing, of community, of sociability, of sense of belonging, on the other it can be used for social coercion and control. It is from within these boundaries that I will expand the notion of the sonic, in order to reconsider those bodies defined as deviant, imperfect, handicapped, incomplete, as the core of the potential that can be unfolded towards an expansion of the shared space, understood in more vibrotactile terms. This exercise will help redefine the notions of "noise" and "counterculture" - or more generally, of resistance and interference, abandoning the usual binary and oppositional paradigm used for their definition, in order to expand towards a more complex analysis of contextual conditions that lead to the stigmatization of certain bodies, communities, and practices.

\section{-SCAPE(-duction)}

The soundscape can be defined noisy, the incessant hubbub accompanying our everyday activities. Noise, if we refer to its relational feature, could be any element of interference or disruption of our soundscape, our habits, our well-acquainted humming and clattering.

However, noisy sounds are not always worth the definition of Noise.

"As a discrete object in itself, noise resists interpretation" (NOVAK, 2015, p. 126), which means that in itself, taken out of the relational entanglement, it cannot be defined. When perceived as disruption, noise is that something we do not recognize immediately, 
it annoys us, it puts us on the alert, it signals something new, different, uneven if compared to our aural customs, however noisy they might be.

Soundscape is here for me a reference to decode social and political realities. Soundscape is mostly referred to and defined according to the limits of human audibility, and it is characterized by habitual and vernacular qualities, depending on the social contexts it helps aurally define. I want to go beyond the boundaries given by audibility, and diminish the preponderance of hearing in the entanglement between individuals and environments. I am interested in looking instead at the relation among bodies, and between bodies and their surroundings, on more haptic terms. This means considering the bodies' potential of affecting and being affected, and re-considering their entire spectrum of capacities, in order to reduce the relevance of stigmatizing terms used to discuss certain deficiencies from the predominant normative hearing standpoint.

This can lead to a more rich and transformative relationship with the body, as a generative core of undisciplined voices.

\section{NOISESCAPE}

Noise has always existed, it is nothing new in humanity's aural environments, but it became a topic of discussion since the industrial revolution, and it emerged as such from the mechanization and the industrialization of the everyday life, generating at first health concerns, to then become that amount of "sounds we learned to ignore", as Schafer states, forecasting a "universal deafness as the ultimate consequence" of our habits (SCHAFER, 2011, p. 110). This doesn't mean that before the industrialization the soundscape was less noisy, we could say that it was differently noisy. As Hillel Schwartz states:

\footnotetext{
Pre-modern communities had not been oblivious to noisy trades, which were exiled to the outskirts of town or subjected to laws restricting the hours during which, for example, grain could be ground, oil pressed, soap boiled, tin and copper hammered, swords forged. And it was not that manmade sounds were innocuous in a world without gunpowder, steam engines, or dynamos: anvils had branged with ear-splitting force; fulling hammers thudded with much the same vehemence when driven by waterwheels; the screak of old windmills could be heard for leagues across Dutch polders (SCHWARTZ, 2011, p. 363).
}

The difference between pre-industrial and industrial era's noises then can be measured in terms of habits. 
Moreover, each and every site has its own specific sound qualities that are affective, symbolic, religious, customary, political, and ecological, defining the aural landscape, giving structure and pace to the everyday life, generating sense of belonging, relationality, territorialization, agency, and behavioural structures. Therefore, sounds not only design and shape activities as much as architecture does, but become also signifiers of social frameworks, activating individuals and communities on different levels. In our customary sonic environments, we get accustomed to different sounds in different situations, and when they cease to be (to "sound") new to us, we also stop noticing them: we either ignore them, or we react automatically to them on account of our established set of habits.

\section{A PERSONAL SOUNDTRACK/A PERSONAL SILENCE}

Soundscapes cannot always be perceived. There are conditions, or ways, of isolating oneself from the aural environment one is immersed into. When detached from the possibility of sharing, within the noisiness of the soundscape and the decoding possibilities offered by cultural habits, the isolated individual is perceived as noise.

I have two examples with regards to this: the possibility of creating a specific and individual soundscape of one's own within the soundscape we share with our fellow citizens, and the actual deafness, which immunizes individuals against the harms (or the seduction, the indoctrination, the contamination, the sharing) of the soundscape of the city life.

In 1979 a new device was introduced in the Japanese market, which was able to revolutionize entirely the everyday aural experience of the people, first in Japan and then around the world: the walkman. "Unlike eyes I cannot close my ears and so cannot avoid my own physical complicity with [the sound's] attack" (VOEGELIN, 2010, p. 49), writes Salomé Voegelin, but the walkman did enable individuals to physically shut their ears with shells of sounds which could be superimposed on the aural cityscape.

It gave people totally private worlds, and before its introduction in the consumer electronics' market, "people never thought they could take music with them and control their listening environments" (BULL, 2004).

In 1989, Rainer Schönhammer, professor at the University of München, conducted a research about the effects of the use of the Walkman in public space. His point of view 
was biased by the irritation he felt towards those which he defined as "earphone beings", described by equally irritated interviewees as "dumb, childish, immature, silly, withdrawn, unwilling to communicate, egocentric, narcissistic, autistic, and so forth." (SCHÖNHAMMER, 1989, p. 129). While introducing his field research about the use of the Walkman, he states that the headphones, appearing strange to the observer, would lead him to "attribute negative traits to that person." And he adds: "the xenophobic attitude evoked by earphones is often expressed in a specific way: the strange being with earphones is not just 'different' but 'isolated'. It is the separateness, the isolation of the earphone being that makes him or her strange." The person who listens to a private soundtrack is accused of erecting walls and barriers, instead of breaking them down. Schönhammer states further: "we see the earphone user as living in a private acoustic world, which we are unable to share. This seems to interrupt a form of contact between 'normal' people in a shared situation, even if there is no explicit communication at all. People with earphones seem to violate an unwritten law of interpersonal reciprocity: the certainty of common sensual presence in shared situations." This thesis of "reciprocity of perspectives" is introduced by Schönhammer in order to clarify further his previous statements: "the subject whose perspective cannot be taken over cannot be 'human' or "normal"' (SCHÖNHAMMER, 1989, p. 130); meaning: the inaccessibility of the individual soundscape of a Walkman user makes his or her perspective impenetrable as well, the consequence of this being the fact that the "earphone being" ends up being described as a social misfit, an alien, in xenophobic terms of irritation, separateness, distance. The "earphone beings" are just a spectators at, and not participants in, what is occurring around them.

A partial immunity from the city rumble is also given by the physical condition of deafness. There is not just one "kind" of deafness, and each deaf individual has a different residual capacity of hearing. The soundscape can be perceived in different ways by deaf people. Background noise makes people more alert and engaged; it is important to hear the small background sounds around us, because they help us to feel alive. The inability of identifying sources or nature of sounds (in hard of hearing people for example) is rather preferable to a total lack of the "backgroundness" of sound, defined as an advantage, since it situates a person in place and time. For a deaf person that very "backgroundness" could be represented by the sensitivity to substrate vibration, relying on more haptic senses. 
However, deafness doesn't exist rigidly according to the deaf/hearing binary, but it implies a whole spectrum, as much as other conditions of life regarded as "disabilities" don't need to be generically opposed to a supposed normalcy.

\section{NOISY CONDITIONS/UNDISCIPLINED BODIES AND ENTITIES BEYOND CULTURE}

I will borrow from Husserl a distinction in relation to the body. Husserl divides the conception of body using the linguistic distinction of the German words "Körper" and "Leib". On the one hand Körper is the "object-body" or "representation-body", that is: the body which occupies a certain space, it is measured and measurable, it could define either animated and non-animated bodies. On the other end, Leib is the body which experiences, the lived and living body, conceived in its wholeness, it is the body that "I am", not that "I have". If the Körper is juridical and biological, the Leib is perceptual, affective, emotional.

Accustomed to the perception of the body as object of medical investigation, as a private property with rights and duties, we lose the contact with the Leib in its full multifaceted manifestation. The feeling of what Leib means is always there, accompanying us, but we put it aside to discipline ourselves according to laws, constrictions, measures, behavioral patterns to obey, moral restrictions.

However, the body has the power of emerging to the forefront of our perception when it betrays its weaknesses, its flaws, its abnormalities, and its pathologies.

In an article published in November 2015 on the Italian weekly magazine of international politics Internazionale, Paul B. Preciado discussed the sexuality of revolutionary bodies. I want to focus on the concept - the perception, the sensation - of body which arises from the discussion on the sexuality of disabled individuals. Using as a reference the book "The Body Silent” by Robert F. Murphy (1978), Preciado discusses the "elaboration of a critical knowledge about physical difference capable of resisting processes of exclusion, discrimination and silencing imposed to those bodies which are considered handicapped." He specifies further that "disability is not a natural condition, but the effect of a social and political process of 'disabilitation' and 'decapitation"'. The systemic apparatuses of societies are built using as a main parameter an ideal 
functioning/functional body which doesn't exist in the lived and affective reality we inhabit, therefore the issue here

is not about establishing a better taxonomy of deficiency, nor about claiming a better functional integration of the disabled body, but it is about analyzing and criticizing processes of construction of physical norms which render certain bodies more vulnerable than others (PRECIADO, 2015).

The concept of "body" is perceived in its profoundness, fragility, sensuousness, carnality, possibility only when described as "deviant", "abnormal", "excessive", "deficient", meaning: divergent, autonomous, subversive. The body which cannot follow rules or fit into measures is automatically assumed as expelled from itself, a malfunctioning Körper seemingly not having the rights of affirming itself as Leib.

The body emerges at the forefront of perception in Sonic Somatic by Christoph Migone. When talking about the stutterer, Migone says that the stutter poses the "accent on the affect and the effect of defect", it represents the foreignness active, visible, and audible, from the inside, it is a proof of difference - and of differential - at the level of the individual.

The indivisibility in the etymology of individual is commonly taken to refer to the individual's wholeness, its unity, its self-containment (including its self-hearing). In other words, it is an individualized indivisibility predicated by the erection of a definitive divisibility from the collective, the erection of an impassable sheath delimiting an interior from the exterior (MIGONE, 2012, p. 120).

The notion of "dividuality" inserts the individual into a collectivity, which is made possible only through "the contact, the encounter, the porosity, the osmosis, the rubbing, the attraction and the repulsion" (MIGONE, 2012, p. 120). The contact could be made audible in a movement of contracture, somehow implying and including, thus exposing, the notion of contract underlying this encounter. The porous and dividual body is defined as "porophile" and when considered within a community arising from that contract of contact, it

is keenly acquainted with its reverse motion, the contraction, the phobic impulse, the repulsion which is fueled alongside every attraction. Nevertheless, if one conceives the body as porous, it becomes impossible to think of an individual without a collective, impossible to keep your distance, impossible to delimit the outside from the inside - one turns into a divisible and diseased dividual (MIGONE, 2012, p. 121). 
The voicing of the repelled body becomes a necessary force which requires responsibility in order to recognize the separateness, the dividuality, embedded in the very act and context of sharing. The (im)possibility of speaking produces "the other which we can recognize even in its full unrecognizability. The separated other is no mere acquaintance, you recognize it as the foreigner from within which rhythms you" (MIGONE, 2012, p. 121-122). The fallacy of the body is perceived as a possibility, yet rejected, demanding indivisibility, completeness, "perfection".

Beyond articulacy and conventions, though, "sounds are sounds and should above all be released as sounds. Everything is in the releasing. There is no score to follow" (MIGONE, 2012, p. 135). Sounds as expression of our somatic (in)dividuality should be considered as inherent, undeniable and undeniably present, in each and every body.

The impossibility of properly articulating language situates the "incapable" individual in a space which becomes haptic, more than aural, generating "a type of relation to and engagement with space which includes the tactile, kinesthetic and proprioceptive senses" (MIGONE, 2012, p. 135). When it is not able to hear itself, the body is exceedingly somatic and present, and it struggles with and in the desire for community, "but a community" which can be present "only in its potentiality; its actualization remains framed by factors of alienation" (MIGONE, 2012, p. 136).

The barrier between the utterance and the acknowledgement of that utterance beyond the boundaries of codified language is most of the times insurmountable. Codifications and canons bias the perception of bodies that utter differently, which sound alien, different, not normalized.

This happens because the other person's point of view cannot be taken over. It is difficult to grasp and understand the impossibility of not self-containing oneself through self-hearing; the excessive speech becomes irritant, or liable to mockery, because it leaks out of norms' containers and categories. The leaking bodies, uncontainable somatic agents, remind us of the fallacy of the flesh. They explode in our face, in all their lack of discipline. They teach us how to differ, but they are confronted with the fright that this kind of divergence generates. Normalcy, equality through repetition, where repetition equals silencing, is something that soothes and reassures us. 
The undisciplined body interferes with the repetitive harmonious normative normalcy. The undisciplined body resonates, vibrates, and makes noise, disturbing with its identity our ableist environment,

It disrupts rather than smoothing the textures of the listener's experience; it demands that the listener engage with its meaning in a full-bodied manner, placing his or her entire being on the hazard. The act of attending to such a voice, the voice of the Other, sometimes sublime and terrifying Other, breaks and remakes the attending self (DRESSLER, 2015, p. 216).

\section{HEARING LOSS / DEAFNESS / SCIENTIFIC RESEARCH}

Soundscape and Deafness meet at the crossroads of industrialization. This doesn't mean that deafness had never existed as a definition before industrialization, but that, together with the vibrational urgencies brought about by the advent and spread of machines, the problem of occupational hearing loss induced by noise attracted medical and scientific interest.

This attention was directed mostly towards the loss of functionality of a "normal" individual within a (productive) society. An idea of supposed normalcy biased the gaze upon the people belonging to the deaf spectrum. If on the one hand hearing loss was defined by doctors and scientists with a variety of categories, and degrees, deafness, on the other was perceived as a monolithic condition of separation, even though in itself it was (has always been, and still is) also in essence varied and differentiated.

Deafness has always been associated with separation, it exceeds the effectiveness of those communication tools we commonly use, which are speech based, and rely on the capacity of learning a language thanks to the possibility of being immersed in it, and of practicing it through a process of self-hearing. When the different possibilities of communication offered by Deafness are not understood, the risk of advocating inclusivity and integration through means which repress the identity of the deaf is very high.

One of the most extreme examples of deviant assumptions regarding deafness is the eugenic plan envisioned by Alexander Graham Bell, son of a deaf mother, and married to a deaf woman. With his ear phonautograph he wanted to educate the deaf so they could speak as if they could hear (STERNE, 2003, p. 36). Bell enhanced the phonautograph designed in 1857 by Leon Scott, which was a machine capable of producing "a visual 
representation of sound - called a phonautogram - by partially imitating the processes of the human ear" (STERNE, 2003, p. 35) with the attachment of an actual human ear instead of a synthetic diaphragm. In this way, according to Bell, the deaf could visualize the sounds that they would produce with their own voices, and through their recognition, they would learn how to modulate and correct the sounds they uttered, and align themselves to the normative speech enunciation. It was, ultimately, 'a machine to hear for them'. The fundamental problem though was that without the possibility of hearing themselves, deaf people could not really use effectively the visuality of the phonautograms in order to train and educate their utterances. Articulated speech is possible thanks to audible feedback and error-correction, which allow to amend the uttered sounds and align them with the inflected sounds of a language.

The approach of Bell was brutal, making of him an advocate of what later would have been called "oralism", and which denied to deaf people the opportunity of using their own sign language, forcing them to imitate the proper articulation of linguistic sounds, and to read lips of interlocutors, in order to become indistinguishable from hearing individuals. Bell's approach to deafness aimed at eradicating linguistic differences. His interests then merged with theories of eugenics, he understood deafness as a human disability to be overcome, not as a condition of life (STERNE, 2003, p. 39).

Luckily, but not without struggles, the Deaf carried on the practice of "an eloquent [...] fluency which was mostly silent" (SCHWARTZ, 2011, p. 707). The active refusal of learning sign language, on the side of oralists, was opposed by the Deaf community with an inexhaustible activity, and activism, in signing on any possible occasion of conviviality. "Many members of the sign language community began to insist that their 'disability' was socially constructed, the result of stigma and barriers in the built environment" (MILLS, 2015, p. 51).

Deaf culture as a concept was proposed in the early 1970's by James Woodward, "capitalizing the term to distinguish the linguistic minority from the audiological one. [...] Hearing children of deaf adults (CODAs) might also be Deaf, if they used sign language and participated in this minority culture" (MILLS, 2015, p. 51). The signed language, then, becomes the hallmark of a culture which was approached throughout the centuries only in relation to the deterioration of faculties of normal people caused by a soundscape 
becoming noisier and noisier, endangered by the attempts of "inclusivity" which hid a will of erasing differences, and normalizing divergent, incomprehensible bodies.

In a Körper-based environment speech builds the political space when the Phoné translates into Logos.

The Logos gains effectiveness, in the hierarchical political realm only when heard and understood, when grasped in its meaning, but also when the divisions between rulers and ruled is recognized and respected. The lack of understanding towards this division and the omission of obedience make of the speech an indiscernible noise, a meaningless muttering.

Dressler quotes Rancière's words “about the order that decides who speaks and who simply makes noise":

There is order in society because some people command and others obey, but in order to obey an order at least two things are required: you must understand the order and you must understand that you must obey it. And to do that, you must already be the equal of the person who is ordering you. It is this equality that gnaws away any natural order" (DRESSLER, 2015, p. 299).

Deaf people in a normative environment exceed the boundaries delineated by the speech as logos. The deaf appear as ineducable subjects, difficult to indoctrinate by traditional (and institutional) means of communication. The exceeding individualities part of the deaf communities appear as deviant characters to be normalized. In 1880 an International Congress took place in Milano in order to decide whether the deaf should follow the oralist method or the manualist one. It goes without saying that the vote approved almost unanimously the oralist method, which was implemented worldwide.

Just quoting here the first resolution of the Convention can give an idea of the violent ableist "inclusivity" promoted by the Congress:

1. The Convention, considering the incontestable superiority of articulation over signs in restoring the deaf-mute to society and giving him a fuller knowledge of language, declares that the oral method should be preferred to that of signs in education and the instruction of the deaf-mutes.

In 1880 started what has been defined "the Dark Ages of the deaf", which forced, according to the approved conventions, the deaf community to communicate with signs among themselves outside of the institutional realm, preserving the language which 
identified them beyond the limits imposed by the structured and governmental environment they were coerced into.

At the end of the 20th Century Deaf communities started pushing for the official recognition of Sign Languages by national governments. However, this acknowledgement would mean including what has always been considered alien according to scientific taxonomies into the everyday normalcy, it would mean nullifying Deafness' status of handicap and accepting it as a culture, it would mean inoculating the virus of the noisy silence the Deaf carry along with them, disrupting the "harmonic" organization of institutions.

The medical definition of the Deaf allows a specific kind of containment and governance, which is also the main reason behind the restraint of most governments around the globe from formally acknowledging sign languages, a restraint that allows to marginalize the Deaf enough to keep them invisible, as they actually are.

Invisible "handicapped" people, which become visible (read: audible) only upon utterance, that one which disrupts normalcy and lets the soma emerge.

\section{FROM NOISE TO RHYTHM / FROM RHYTHM TO THE BODY}

\section{Noise is "the chaos that resists social order; the unintegrated} entities that exist beyond culture (NOVAK, 2015, p. 126).

Noise is the undisciplined body which marks the distance from a so-called normalcy, with the potential of expanding the possibilities of our senses, prescinding from the mere aural ones, and learning how to connect ourselves to the world on another level, the vibrational one.

Noise is not a finite object, or the end of a process, yet it is a field of possibilities.

For Goodman, the sonic landscape is a virulent aural space which keeps us under siege. In this landscape power is deployed through the articulation of, among many devices of coercion and terror, holosonic control, audio virology, and the ecology of fear.

From the glossary of Sonic Warfare:

Audio Virology: theory and practice of cultural virology operating at the level of affective contagion, as opposed to the cognitive epidemiology of memetic 
Ecology of Fear: phrase coined by urban theorist Mike Davis to depict the affective climate of catastrophic urbanism, the city and its control systems as affected by the threat of natural, technological, sociopolitical, or economic disaster

Holosonic Control: the convergence of direction ultrasound technologies with preemptive power for audio virological objectives. Produces the effect of déjà entendu, among others. (GOODMAN, 2012, p. 195-198).

Goodman links the emergence of the contemporary city as a site of warfare to the notion of Kittler's military-entertainment complex. Most of the technologies we use on a daily basis were first developed as military devices and translated into the civilian realm without what Kittler defines the "talkback-capability". This means that these technologies become accomplices of pre-programmed one-way processes of affection, seduction, and indoctrination. This is the case of sonic branding, of Muzak, aut similia.

In a political framework, the deaf are deaf to the hearing people, but they are also deaf to orders. Their potential, despite the condition of "handicap", could be equalled to the potential of the communication and mass-mediatic machine, which is deaf to us. The potential of the deaf is exactly this being immune to the audible surreptitious virology of the sonic branding of our soundscapes. However, considering only the binary separation of hearing and deaf is rather reductive, since "the bandwidth of human audibility is just a fold on the vibratory continuum of matter" (GOODMAN, 2012, p. 9). It is possible to consider the sonic realm beyond the thresholds of the human audibility, including hyperor infra-sonic frequencies. Infrasonic sounds, lower vibrotactile frequencies, are easily felt by deaf people, and their sensitivity towards them is usually more refined than the hearing bodies.

In this vibrational realm we can focus on the vibrant matter which constitutes reality, posing the perceiver and the perceived on the same level, in a relation of mutual prehension or mutual objectification" (GOODMAN, 2012, p. 92). The body, as the basic prehensive module of the micropolitics of rhythm, becomes the only prerequisite for existence, being the transducer "of energy and movement from one mode to the other" (GOODMAN, 2012, p. 27). The transduction process compels to focus on the potential of the body rather than on its definition. It is for this reason that instead of giving primacy to human audition, the sonic experience should be extended towards an ecology of vibrational affects. microrhythmic) nexus of sensory modalities that constitutes an encounter. 
The affective sensorium of an entity becomes a rhythmic transducer composed of not just the five exteroceptive channels that open onto the external environment, but also the viscerally of interception, which is sensitive to intensity minus quality and in a sense preempts exteroception in that it makes decisions before the consciousness of extensive sensory objects fully emerges (GOODMAN, 2012, p. 48).

In this sonic landscape the "disabled" bodies of the deaf have an advantage, and retain a higher potential of affective transduction, prescinding from the aural qualities of the environment, and allowing körper and leib to be considered at the same level.

I will mention now the work of contemporary artist Damir Očko. The artist investigated in his video work themes related to sound and language, expanded in their vibrational features, including the body conditions of deafness and stuttering. In his video TK the bodies are presented in specific conditions of fragility: on the one hand an old man, writing with a trembling hand sentences like: "In Tranquillity the word is shivering. [..] In Tranquillity each stone has a purpose. [...]" etc., on the other a group of young muscular men half naked in a winter landscape shivering because of the cold.

\begin{abstract}
In a time of global insecurity, uncertainty, injustice, turmoil, anxiety, and fear, 'the shivering' body is a metonymical figure intersecting different imperatives, reflecting imposed personal and social relationships. Shivering becomes a mechanism of resistance, pointing to the procedures of control and lack thereof, a metaphor of interaction between the society of control and the violence it produces (BRANKA BENČIĆ, 2014, p. 22).
\end{abstract}

The fragile body is presented in its vibrational state, resonating with its internal or external conditionings. In both cases "the shivering - subversive, treacherous, disclosing - becomes like a rhythm" (BRANKA BENČIĆ, 2014, p. 22) and it uncovers the vulnerable flesh we all are made of; watching this video causes unease and angst, it reminds us of what the body actually is. The shivering, rhythmical, body, is here moving in a way which suggests a primal form of existence: vibration.

\title{
ACTS OF SILENCING
}

Silencing is a display of power which doesn't necessarily require silence.

It can be deployed in a surreptitious as much as in a more overtly repressive fashion.

We could say that somehow all the restrictions imposed by parameters of the measurable ideal körper can constitute a kind of silencing. 
An interesting work by Katarina Zdjelar, titled Stimme somehow explains what does it mean to give voice back to a silenced voice, that is: a silenced body. In this video work Katarina follows a voice coaching session. In this session the coach modulates the patient's posture and movements, showing the process of voice emission as a construction. Katarina says:

\begin{abstract}
The piece considers when our voice becomes our personal property. Where does the voice begin and where does it end? Who is speaking when we speak, and who is entitled to speak? For that I have followed the sessions of voice modulation, during which the client is promised to gain her natural voice, that is, a voice which is released of its existing socio-cultural markers and constraints. The piece circles in the time and space of the vocal attribution. Oscillating between voices and never arriving at the desired destination, Stimme focuses on a liminal voice; a voice between culture and nature, something in between the material and corporeal act of producing voice, and the social process of receiving voice. [...] We follow the way voice inhabits the body, and we hear the way the same body lies in the voice. On instances, the coach's hands do the work of her clients' bodies and therefore appear as an extension; a prosthesis. Each body part has its own sound, which needs to be tuned. Thus hands become, in certain instances, a hearing aid of the coach, like an extra pair of ears that examine and adjust the sound of the voice (ZDJELAR, 2014, p. 21).
\end{abstract}

The voice lies between a natural status and a social one, the latter resembling somehow what has been mentioned regarding the self-hearing process of refining one's own speech. A voice which has learned how to functionally respond to a certain environment, and which is not able of freeing itself from the constraints imposed by that very environment, is somehow a silenced voice. A voice responding naturally to the specificities of the body it belongs to, without effacing discrepancies, flaws, and traumas is not a silent one, because of its capacity of resonating from within, without necessarily being deaf to the surroundings.

\footnotetext{
What we witness in Stimme is the manufacturing of natural voice, the hard labour of producing natural sound. A contradiction in terms. We are situated in the middle of the power struggle fought on the battleground of language and voice, with all of its entrenched and enfolding history. [...] It is difficult to tell if there is a voice without all its historical, cultural and social underpinnings, mostly because its destination is speech. But if there is such a voice, can we actually do things with it? Is that voice operational? And what remains when all markers are removed? Is there voice beyond representation and can voice be heard without its markers? (ZDJELAR, 2014, p. 22).
}

The questions the artist asks make sense insofar as they relate to that consideration of the body as operational, functional, measurable. The non-operational voice, the natural voice, is hardly definable in terms of functionality. And it is here that its value, in opposition to the silencing methods, lies. 
Another kind of silencing is deployed through the repetition of audio-viruses of any sorts (from sonic branding, to muzak and, nowadays, algorithmic taste making) babbling in the ears of people, manipulating their ideas by worming their brains. In these instances, bodies are silenced through "the mode of power implied by repetition [which] [...] eludes precise localization; it becomes diluted, masked, anonymous, while at the same time exacerbating the fiction of the spectacle as a mode of government" (ATTALI, 1985, p. $88)$.

The Attalian idea of silencing the masses, harmonizing society through ordered speech and music, is a human construction which avoids one and only truth: the fundamental noisiness of bodies. The undisciplined speech of the deaf, as much as of other non-normative and non-normalized bodies, is there to demonstrate that to us.

Beyond music, beyond the audible, the body inherently retains the possibility of being "noise", despite the risk of being wormed, silenced, normalized.

\section{ACTS OF NOISING / INTERFERENTIAL EVERYTHING}

The silence/silencing we described before is an imposed silence, originating in noise or the fear of noise. "Everything is noise, and noise is in everything" (HAINGE, 2012, p. 2). Noise as a phenomenon could be boiled down to the word "interference", and in its barest form it could be applied to almost anything.

The interferential feature triggers questions about the possibility for Noise to be the most suitable weapon for fighting hegemonic systems.

The capitalist machine, as a formalized system which determines our lives, has a capacity of resilience which allows it to inoculate enough viruses that they easily immunize themselves from noisy disruptive potentials. The result of this immunization process is the normalization of the noisy Noises, and their introduction in well specified systems and contexts, which somehow nullify their destructive capacity.

I don't think it's credible to attribute to noise a directly anti-capitalist political valence. The political significance of a phenomenon is often ambiguous (I say 'often' rather than 'alway', because there is nothing ambiguous about the political significance of an English Defense League rally, for instance). Only rarely can it be unequivocally deciphered or straightforwardly translated into an identifiable political stance, And of course, it's not only content that is political, it's also the form of political deciphering: it's not just what something is but how it is interpreted that is 
political. Ultimately, this means that nothing in the realm of cultural production is inherently pro- or anti-capitalist [...]. If noise harbors any radical political potential, then it needs to be elaborated via a process of interrogation, which would involve working through question such as: What is experience, given that capitalism commodifies sensations, affects, and concepts? What is abstraction, given that capitalism renders the intangible determining while dissolving everything we held to be concrete? What freedom are we invoking when we proclaim noise's 'freedom' from the alleged constrictions of musical genre? This is just to say that the 'destruction of capitalism' evoked in your question certainly won't be achieved via any form of spontaneous or participatory experience. It would require the development of a political agency informed and instructed by cognitive achievements obtained over the course of a critical collective investigation. A 'politics of noise' commensurate with such an ambitious task presupposes cognitive discipline, communal investigation, and collective organization (R. BRASSIERE).

The interference I am interested in, and which I discussed so far, is the one of the soma rendered visible in all its spasmodic mode, the one which disrupts the fabric of the everyday slipping through the grid created by the plain opposition of noise and silence. It is the interference which is deeply entrenched in its systemic contexts, and which noises from within the processes of analysis and exposure of the mechanisms that produce its "disturbance".

\section{NEW VOICES / CONCLUSION}

Noise is (or used to be) the emblem of counterculture, we could call it a countercultural weapon.

However, it could be easily normalized, included, coopted.

I don't intend to deny the power of noise as a countercultural weapon, but I want to try to envision another way of displaying countercultural thoughts, in interferential ways which don't need to be also defined noisy, but possibly: "not noisy Noises"; that is, "new noises: new voices".

This short journey through the environmentality of affects, inhabited by bodies in resonance with each other, bodies considered in all their potential, even when exceeding the limits enforced by institutions, showed how countercultural potential is inherent in each and every body, beyond the measurement and the definitions imposed by medicine or society. 
Counterculture is here understood as interference, disruption, asymmetry, it is the unsolvable aporia which lies at the very core of the human, and the struggle between noise and silence. It is the excess.

Excess is a feature which can be easily applied to Noise. Noise is something which interferes with a message and exceeds the message itself. Noise exceeds definitions. It is ungraspable, definable by what it is not.

Excess is a feature which can also be applied to a body. It is the case with the bodies we tried to depict, not abiding by lawful pre-programmed ways of functioning. Deviant bodies, which swerve, instead of falling perpendicularly, and with this twist they generate invention, they create.

Bodies swerving. Outside binaries. Bodies derailing.

Derailment is what's needed in a cultural context dominated by numbers. Vibrating, being put out of balance is what we are scared of, and we turn to what soothes us, accomplices of a ruling machine that doesn't need to function anymore in a top-down fashion, it has absorbed the bottom-up, the proliferating, the hacking, the horizontal, it is everywhere. It can detect the potential of subversion in the loudness of Noise. "Noise destroys and horrifies, but order and flat repetition are in the vicinity of death" (SERRES, 2007, p. 127). Noise is easily detected, it cannot be hidden, and anybody can react to its "loudness". This has led the machine to learn how to counteract. It has rendered noise powerless, it transformed it into repetition, into order.

My vision of a future counterculture is a silent one, inherently divergent, like the Deaf, impossible to assimilate and normalize. The Deaf mode of existence is one of the noisiest we could think of. It can imitate the silence which is imposed to us, while being capable of resisting the attacks of the audio virology, of one-way commands, and it can sound as undisciplined as a voice which resonates just with its own body, a voice which has never learned how to fit into an ordered environment.

The future counterculture is in the traumas of the flesh, in the deviance of bodies. The potential of counterculture is in their fallacy, in their struggle for life.

Each deviance is excess.

Each excess has its own voice. 


\section{FROM LIFE TO THE PAPER / FROM THE BODY TO THE STAGE / ANNEX}

Consider this an annex to this paper. This is an interview to an Italian choreographer, Laura Simi, based in France. Laura, a Deaf dancer, is part of the company Silenda, together with her partner, Damiano Foà. She encountered my writings (my first book: Strategie del Rumore. Interferenze tra Arte, Filosofia e Underground, Auditorium, ed. 2015, and this paper soon after) and got in touch with me. She used my thoughts in the creative processes of production of her last two shows, Sonore (2015/16) and Fenomeno (2018/19). After almost four years of digital correspondence, we met in Paris in October 2019, where I attended the premiere of Fenomeno, in which I recognized the content of this paper.

I decided to have a conversation with Laura and add it to this paper, because I deemed of the utmost importance to acknowledge the artistic outputs stemmed from contamination, in order to reinforce with a testimony from an embodied experience all that I have elaborated above. The mission of a thinker, especially a hybrid one, is to function in a mycelian fashion, to spread and fruit in non-linear ways.

I want to zoom here into the performativity of the deaf body, Laura's body, and the translation from the page to the stage, through sounds, vibrations, hiccups, rhythms, mishearings.

Martina: "I want to start with a very simple question in order to introduce your encounter with my work and how it affected your research, and we can later dive deeper into the many aspects that link your productions with my writings. When did you find about my book?"

Laura: "I first read about your book on social media between 2015 and 2016, through an event for a public presentation of it. Driven by curiosity, I bought the book and sent you an email, craving to start a conversation with you. When I contacted you, I was working on Sonore, and for the first time I was diving into the depths of what I consider my biggest fragility, but also what attracts me the most: sound. When I read your 
book, many possible paths opened in front of me, and your writing shed a light on so many topics that were new to me at that time. Moreover, your words somehow explained all those emotions I felt, but I couldn't find words for. From that moment on, your book has always accompanied me during rehearsals. I would pick it and read it out loud to my collaborators. Even for the piece after Sonore, Fenomeno, the book, together with 'New Noises New Voices', has been a fundamental companion for creation, a source for creative ideas. Your writing were always there, as a pulsating presence, alive. Your thoughts and stories, your interviews with Noisicians, the research into the philosophical and sociopolitical fields, together with the discovery of Muzak and other contemporary forms of sonic thoughts and expressions, gave me a great artistic motivation. My biggest realization though was that sound is mysterious and ungraspable. This acknowledgment opened choreographic possibilities that became very important for me.

I have been interested for a few years now in the complex and mysterious connection between dance and sound, from the very specific and situated standpoint of a deaf person. Having been a dancer for a long time, this connection has always existed in me, but I never really processed it consciously or rationally. In these very last years, I decided to tackle this topic differently, inserting my embodied experience into the creative process, laying myself bare. As a hypo-acoustic being, I would constantly ask myself what did it mean to have malfunctioning ears in relation to music, and I reflected deeply on the strategies I found and implemented to practice and work with dance throughout the years. The fact that the sound traverses the body, and that the body is like an extended ear, a sponge for sounds, results into dance being a secretion that oozes out from this vibratory encounter.

When I was a kid I would encounter and behold so many anatomical representations of the ear, in clinics, in audiology labs, in specialized doctors' studios. I developed a very specific fascination for this organ, which I consider an anatomical gem. As a consequence, I worked a lot on the structure of the inner ear. The tiny bones inside of it, constantly moving, would suggest to me rhythmic themes, the stereocilia and the liquid inside of it would evoke a secret, precious, and fascinating landscape.

I got struck by a sentence you wrote: 'In a political framework, the Deaf are deaf to the hearing people, but they are also deaf to orders'. This sentence for me contains a 
sentiment I have always felt throughout my life, a feeling of unconscious rebellion, of impermeability in relation to some words or phrases I was sure would hinder me, or repress me. Somehow deafness protects the psyche.

And this somehow connects also to my interest in why do certain musics or sounds trigger very specific emotional states. Or even, memories of places or situations, even when the hearing is not 'perfect'. In this specific case, the collaboration with a composer has been fundamental for me. He has been able of recreating the sonic chaos, but also the silences, those very silences the Deaf people experience, which are somehow compressed, mineral and liquid, very difficult to explain and put into words in order to be then translated into sounds by somebody else. All of these physical sensations are interesting because they summon a sort of 'primitivity', a state of infancy, of not knowing, that lies at the core of all of us. These are the moments when we can recognize humanity in its entirety, and when humanity in its entirety can recognize itself, in its most intimate essence. I am sure the public can feel this very clearly through my pieces.

From the choreographic point of view, sound leads me through different paths, and it does awaken very specific processes during the creation. The body is slower than sound, and it translates into a continuous struggle between two temporalities. Sound reaches you faster than a bodily movement, and this is also what renders the creative and compositional process more interesting. I want to quote here Fernando Pessoa's words, which I learned from Wim Wenders' 'A Lisbon Story': 'In broad daylight, even the sounds shine. [...] I have wanted, like sounds, to live by things and not be theirs'."

M: "Can you tell me a little bit more about the collaboration with the composers for your last two pieces?"

L: "The history of this creative process is a bit lengthy, but I'll try and summarize it for you.

As I mentioned, I have always been interested in the relationship between sound, body, and gesture. In 2014 I decided to zoom into this relationship and magnify it. At the beginning I didn't tackle deafness, but I approached the topics in more general terms 
instead. I worked first with the musician Jean-Noël Françoise, with whom I created a piece titled 'Shut Up', in which we staged a war between two entities, Music and Dance. It was about the authority of sound and the figure of the musician in relation to the dancer: he would create 'sonic traps' for me, from which situations and actions swaying between tenderness and violence emerged. He would make my hearing aid ring, and it would amplify its sound. The hearing aid has always been a fascinating object for musicians, it seems. After 'Shut Up', I performed a duo piece with a child, accompanied by a pianist who played Bach's Preludes. I wanted to explore the notion of prelude, etymologically pre-ludic, before the game, in relation to childhood. As I worked on these projects, I thought about entering the theme of sound from a more corporeal standpoint: how the body absorbs sounds. I was getting closer and closer to talking about deafness, and I have to admit that I realized how firmly and for how long had I resisted this drive. I was against working on deafness because I was scared of being used to sell tickets, or to be treated with pity, of being inserted in circuits of "inclusivity", which I am very dubious about still today. I was a bit ashamed of the autobiographical aspect, of presenting my own story as special, when I think it's just one story among many others. However, I had to accept the fact that deafness had shaped my dance, my artistic personality, and this is sure and crystal clear... clear exactly like an audiogram! Moreover, the more I read about sound and sonic researches (including your book), the more I told myself I had to tackle this issue. That's how I got to Sonore in 2015/2016. At that time, I wanted to create a group piece, a choral work, and I collected material in order to score the choreography. I tried to explain to the dancers what is it that you hear, as a deaf person. This task turned out to be very difficult, especially for them, because it was impossible for them not to 'pretend'. For Sonore, we collaborated with two musicians, Perig Villerbu and Jean-Noël Françoise, that Damiano and I had known since our arrival in Normandy. We carried on a research on sonic waves, on vibrations, on white noises. We started finding and discarding resources, we cut and pasted voices and rumbles, built a system of central diffusion, and an external one, in quadraphony, creating bumps among the speakers. The speakers were the symbolic objects of the piece, they were the actual scenography, they constructed and limited the space. After a dream I had one night, we added two giant ears, two sculptures. Those are ears which listen to the space (also a reference to Bosch's drawing 'The Forest that Hears, the Field that Sees'), two giant ears adding an ironic touch, underlining our 
endeavor. At first, dancers were dragged into a vortex of sound, a maelstrom, and musicians would elaborated sounds triggering specific emotional states, sonic waves designing the space, in a hypnotic way, ordered by a score that grew in intensity, a primal sound that would evoke somehow the dawn of humanity, the movements of planets, directions and circulations, unison and canons that led eventually to a condensed and disordered chaos. From there, everything became language, and we mixed alphabets, signs and gestures, that we researched together with the dancers. These movements referenced sign language, but also ancient gestures, propitiatory gestures, rock music gestures, magical gestures, religious gestures, rage gestures, insults, protest gestures, musical gestures, marshallers' gestures. We also created a big partition on the notes of Demetrio Stratos' 'Le Sirene' - the sirens, a very important sonic reference from mythology. Each of the performers would stand on a speaker, like a pedestal. In one scene, which we called 'the dictator', we would gather all the speakers in the middle of the stage, creating a mass that resembled a totem, which would erupt like a volcano with guttural sounds and voices, a mix of real voices of dictators' from the past, meshed together in order to create and unsettling conglomerate, oneiric yet very real. We also added a piece by Alfred Schnittke, a piano piece which reminds of the black and white movies, the war, and two figures: another dancer and I, upside down, with a face drawn on each of our backs, the faces' mouths taped closed, grotesque and odd. We would move the speakers in the space, creating mutant sculptures made of sound and powerful vibrations. We aimed at giving the speakers an anthropomorphic connotation, the membrane became a skin, a tympanum, and we connected them with the idea of volumes (as sonic volume, and as volumetric articulation).

There's a lot happening in Sonore, and in the process we sourced from music archives, broadcasts, "Art of Noises" by Russolo, old movies which presented interesting voices, like I Cavatori, a documentary from 1958 about the marble quarries in Carrara. In this movie, the shouts of the quarrymen reminded me of tapes I would listen to from an old tape player when I was a child, and the explosion of the mountain conveys a very powerful, sonorous, and vibrating image.

Despite these very specific references, the piece resulted into being very abstract, and the light design, very geometrical, contributed to this outcome, together with the fact that it was impossible for me to convey all my feelings and sensations to the other dancers. 
This impossibility led to Fenomeno, a piece in which I continued my research further, with more intensity and freedom. Perig Villerbu collaborated with me for the sounds of this piece. We explored new paths and dived into more archives, and, almost by chance, I came across my old journals. At the beginning I would keep these childhood diaries in my studio, I would read a page or two, and sometimes share fragments of them with Perig, until he proposed to record them. At first I wasn't sure about recording my voice, because I deeply dislike it, but Perig suggested that it was necessary for me to expose myself in this way according to the creative trajectory we had been delineating in the last years, and talk about my childhood with my own voice. That's how some of the intimate events of my life entered the piece, together with a more general and historical picture of those times. We gathered more texts, phrases, we cut and pasted, repeated, shortened, repeatedly while shaping the choreography. Eventually, this is a piece about communication, it is about a being that wants to say something out loud. Neil Callaghan, a choreographer who helped me out throughout the process, wrote to me in a private correspondence 'It is like these speakers are memories, an archive. [...] I think of the little white speakers as teeth and for a moment the whole stage becomes like a mouth, a resonant chamber' and 'Communication is important. Sometimes very direct, sometimes more of a landscape. Sometimes the piece feels like a protest, a rallying cry, a demand, and at other times it feels like swimming in a personal archive. [...] It is a technological landscape of microphone and speakers, but it is a very human piece, very touching'.

Some material aspects of Sonore can be found in Fenomeno, but the latter is more of a self-portrait that evokes also an external world that pushes against the dancer. Fenomeno evolves through repetitions, modules, swinging, oscillations, fragmentations, fractures, transformations. It is a mental landscape and therefore it is a bit more disorganized than Sonore, it's a forest of tangled cables, it is unstable, it evokes a ruined city, a place where imagination can take off. Within the piece, I created obstacles in order to openly deviate the dance practice towards other directions. Reminiscences punctuate the piece, like a piano piece for Schumann, summoning the way I would dance when I was 7, a dancing style and memory I revisit and relive very often. I need to confess that the piano has been an instrument that has accompanied me on a daily basis, during the early training for classical dance. I think it triggers something within my unconscious, and its sound has been the soundtrack of my intimate decision to continue dancing. With 
Perig and Damiano we sculpted and manipulated all the materials we found in order to weave a dramaturgical thread, correcting, speeding up, cutting, slowing down, giving space to silences, or in general to moments in which there's nothing to see, and the audience should listen, or just pay attention. I don't consider Fenomeno a piece or a show, I think it's an experience in which the viewer is enveloped by the energy we create. Perig also composed several sound pieces exploring the sonic spectrum, besides the collages he made using multiplied and de-constructed voices. Some of the leading concepts (words, phrases) we would refrain and return, picked directly from your texts were: bodily felt, infrasounds, chaos, undisciplined, vibrations, sonic warfare, architecture, speed, virulent aural space, micro-rhythmic, viscerality, interoception, palpitation, contraction.

Many sounds that Perig worked with are imperceptible. Those are sounds extracted from the old archives, both radio and film archives, that I mentioned earlier, together with records, and recordings Perig produced himself. They exist, and they take part into the composition of a poetic mass, in which the audibility of the individual sounds is of lesser importance than their collective presence, they exist even when hidden.

Sonore and Fenomeno are connected but they are also different. One is a formal and choral experiment on sound. The other is an intimacy that erupts, in the moment it is revealed. Music and dance rub against each other, and through this rubbing they compose the piece together. We experimented a lot through improvisation, starting from themes or prompts proposed by me or by Perig. Sometimes we also followed trajectories which were perfectly planned and scored, and repeated them until we found something new within the repetition. Many details of the piece stayed the same since the inception of the creative process, they just got confirmed and fixed along the way, while around them we allowed mutation and unexpected discoveries. This process takes time, and in total we worked on the piece for two years and a half. However, the gestation has been way longer, because I had been ruminating about the themes contained in it for many many years. We would write, talk, discuss, put ideas aside to let them grow ripe and ferment, we would go back to them, pick them up again..and in this process, time flows forward. The show, eventually, is just the tip of the iceberg, and, to be honest, it is not even the most exciting moment of the whole process, which is definitely more intense and tragic, sometimes beautiful, sometimes extremely ugly. I think of a couple of quotes by Joseph Beuys, to which I can relate: 'I feed myself with waste of energy', and 'That is why the nature of 
my sculpture is not fixed and finished. Processes continue in most of them: chemical reactions, fermentations, color changes, delays, drying up'.

I asked myself more questions, throughout this process: Can sound be a vessel for thought? Can it be a tool for observation? What happens when we stretch the space between the visual and the auditory? Can we choreograph this space? Can musicality inform us about systems, structures, or individual behaviors? Can a collective musicality have anthropological qualities? These are all open questions for me that could offer new lines of research."

M: "Some of the questions you ask bring up some themes that I have been reflecting upon. For example: the space that opens up when stretching the visual and the auditory, and perhaps a seeming contradiction regarding the primacy of the visual on the sonic/sonorous/auditory. The deaf body develops an acuteness of vision, for obvious reasons, but at the same time it furthers its capacities and sensitivities towards vibrational forces. According to me, this is a fundamental node that could help to start answering some of your questions. The able body doesn't ask itself too many questions, and this could be one of the main reasons it results more keen on being lulled unquestioningly into following the choreographies of power. The able body is accustomed to not having obvious limitations, and this is a systemic issue, of ableism in relation to the creation of a world that has been designed and measured according to the shape and figure presumably uncontaminated therefore impossible - of a Western heteronormative white male. If we wished to oppose a counter-choreography to the choreography of power, which implies the un- and sub-conscious development of programmed responses to specific environments, communities, cultural expressions, where could we start, according to you and according to your experience as a deaf dancer?"

L: "Perhaps I would start from abandonment, from giving space to a non-civilized body, a 'primitive' body which feels the rhythm without dissecting it and ordering it, a body that follows the proposal for movement as sheer movement within and through the body, reflecting the inherent intelligence of the body as a rhythmic vector. A body reaching trance, inter-mediating" 
M: "I recently found a wonderful metaphor at the beginning of a book which discusses the non-linear and fungal trajectories of life in the ruins of Capitalism, and the metaphor is about polyphony. Polyphony is accounted as the most suitable way to tell stories of the complexity of the world we inhabit, a world in which micro-stories with different temporalities merge into the bigger narratives of power, which in turn offer only one progressive line of evolution. Power, as I also elaborated previously, could be described as harmony, a single line of melody, something very easy to tune to, easy to follow, somehow also unimaginative. However, we can tell the stories of this world only following different lines of melody, even discordant among themselves, which can unite in a conglomerate that can result into dissonance and chaos, but in which we could recognize patterns, even euphonies, acknowledging the fact that those patterns have nothing to do with the 'harmonic monotheism' of the big narratives of power. This also somehow connects to the dissonance you embody in your practice as a deaf dancer, in the translation of what your ears perceive, which is very different from what hearing people perceive (even though we all have different hearing capacities, even within the spectrum of those we define as able bodies). Have you ever thought of your practice in these terms? Perhaps the collective musicality you ask about could be an exercise in polyphony?"

L: "I definitely think so! There's a first dissonance, happening between what the spectator hears and what I hear. After all, it's a whole life that I experience this 'decalage', this gap, but not only for sound. In general with my practice when I am on stage, I discover things that I couldn't be able to identify without the reflection in and the resonance with the spectators in front of me. It is all very mysterious, and some aspects of this resonant process stay ungraspable to me.

For what concerns dance in general, in the last years contemporary choreography has focused on mass, symmetry, rhythmic order. Dance is considered a 'fragile' practice, and ordering it makes it more acceptable, easier to fund and sell. However, experimentation is being re-discovered by many, as a reaction to cultural policies that avow efficacy, productivity, immediacy, utilitarianism. We reached a point of saturation in several arts, there is no time left to search and research, to spread ideas in the right 
way, to evaluate with rigor what should be rendered visible and what to hide: this process of selection and reflection takes time. Everything became spectacular, and it needs to function perfectly, it needs to be ready quickly. The machine ends up grinding very quickly into burn out those who follow these logics."

M: "I want to open a little breach for hope: up until a few years ago, we relied on big narratives, in politics, in art, etc. Now we move and exist in a hyper-fragmentation of reality, in which several truths co-exist and intersect, or run parallel (polyphony again..), and perhaps novelty could be found in the micro-narratives which feed into the wider narratives, and contribute to their composition. As in your case, with Fenomeno, the fragments from your biography are presented as a very touching testimony of the embodiment of a stigma, a life lived 'out of phase' from the 'normalcy' defined by the medical system, a fragility that, in its contrast with the big narratives of society and institutions, connects with and gives substance to the multilinear, and fragmented, history of Deafness as a mutant culture, emerged from the ruins of systems designed for able bodies, according to medical taxonomies which are wrong, in the sense that they exclude other modes of existence from the dignified realm of Leib. They exclude polyphony."

L: "Thank you for writing this. I have always avoided victimizing my position. My mother educated me in order not to drown in self-pity. I have two sisters, Deaf as well, and we had to give strength to each other, and try to find the humor in the situations we found ourselves into. This doesn't mean that we aimed at isolating ourselves, or at developing hatred towards hearing people. It was just hard for us. For example: when I was a kid, I was told clearly and repeatedly that I would NEVER be a dancer, that I would NEVER achieve certain goals I set for myself or dreamed about. Luckily, during my teenage years, I met open-minded people in the field of contemporary dance, which were experimenting outside all norms as a matter of principle, and never stigmatized my deafness. I remember a solo I danced at Turin's Teatro Nuovo, choreographed by the hyper-contemporary Torao Suzuki, accompanied by very abstract music including very acute violins that I couldn't hear. Basically, I never heard the music as I danced, I have no idea what it sounded like, but Suzuki just sent me on stage... just like that.” 
M: "Do you see in the analysis of micro-narratives a possibility of experimentation, of creating something "new"? Something meaningful and tangible for the spectator, but also relevant for your artistic field? An artistic mission as a localized practice? And I want to connect this also with a wider perspective regarding the categorization of specific practices (which we could define generally as non-normative) into specific buckets - in this case 'disabled art', a categorization which also removes the possibility of acknowledgment of its full integrity and dignity, within the polyphonic view of the world."

L: "I certainly think so. These micro-narratives are always re-contextualized, refreshed, by new ways of expression. I don't think the 'new' is in finding new ideas, but it lies in new ways of working on ideas, in the availability of the practice, its amplitude, it needs to be wide, very wide, in order to be able to include also the past. This is why the crazy experimenters in the $70 \mathrm{~s}$ are fascinating and inspiring for us: they did not want to make 'new things'. It was their attitude that was new, the way they worked and played with what they had, inverting and subverting, taking the time to fail, to exchange with others, with the rhythm of the cities, with other arts, with literature, with philosophy. They were not aware of the impact they would have. A big part of their freshness was the abolishment of the ego. In those years, if artists appeared as self-focused and selfcentered, they were not well accepted. I studied also in New York, in Nikolais' school, and I remember how they dismantled the students' egos, sometimes a bit too harshly. However, when I think about it, this was such a big thing: putting aside the ego to leave space to movement, to the idea and the intention. Nowadays, the opposite is true: the selfreferential and self-centered artist sells better, narcissism is a big hit. Personally, I have always been very discreet, I was not interested in the ego: this was due to my education, but it was also due to the fear I felt because of my handicap. The world kept telling me I wouldn't succeed as a dancer, but I managed to find support in those spaces which didn't focus on egotistic practices, and that's how I managed to better myself, finding new wide landscapes for my artistic research. 
I am also skeptical regarding the categorization of disabled arts. I will take part in a few 'inclusive art' festivals, and I agree on putting a halt to this logic of divisions. On the one hand it is interesting to see how these practices developed into their own niches [and the empowerment they can have in re-appropriating the terms that define them] but on the other I detect some marketing strategies that disturb me, because they can cause some dangerous drift in perception, besides catering to specific viewers. I am dreaming of a world in which a theater director is Deaf, a president is Blind, a dean is Paraplegic. Society disregards the precious inputs that could be gained from other 'categories' of existence, new temporalities and new modalities of practice and management, with more sensitive and original answers to problems in politics, education, arts."

M: “Ableism intersects with many other forms of systemic exclusion, of stigmatic categorization, rendering polyphony even more complex, especially when we make an effort to imagine a new world, more expanded, more ample, where voices, able and nonable, of Western and non-Western ancestries, cis- and queer, coexist. I think of the term 'inclusion' and how it can contain a lot of violence, when implemented in ways that stress the negation and renouncement necessary by the person which is being included, it implies a fundamental unevenness, and superiority of the category that includes. It implies that you can have a place in the world only if you accept the stigma that is assigned to your body."

L: "Yes, inclusion in these terms could mean, from the position of the privileged or powerful, to 'make a sacrifice' in order to include 'odd' bodies, and make just enough room for them to survive, but not thrive. It is always very difficult to find the right words, but I would stress what I mentioned earlier regarding expanding the practices, making room in order to include the past, and rethink the past, even when it is uncomfortable to do so. Moreover, I would suggest to always look at disabled bodies, like I do with my students with 'handicaps', to get inspired by their strength and patience, their boundless love for the other, their striking capacities for imagination, but mostly: their different temporalities for action, something I learn from, and something that is teaching me how to change my habits, and consequently my way of thinking." 
This conversation with Laura exemplifies how a polyphonic discourse regarding the potential of the voices of undisciplined bodies and entities beyond culture can lead to the development of practices which deconstruct definitions and paradigms, expanding their scope in order to make room for the "other", even when the "other" is within ourselves. Discussing the possibilities contained within what society taught us to define as deviant, non-normative, or disabled can be a humble act of support and empowerment. It leads to the decoding of our (sonic, in this case) landscapes, and to the analysis of institutional modes of silencing, besides giving hints towards the possible paths we could undertake in order to find a new, wider - yet specific and localized - definition of counterculture. The new counterculture recognizes the traumas of the flesh, and accepts the voices exceeding the norms as part of a collective polyphonic endeavor of telling the stories of our present, projecting them towards the future, while including the past, our individual and collective past.

\section{References}

BENČIĆ, B. In: BENČIĆ B., DROSCHL S. (ed.), Damir Očko: Studies on Shivering, Graz: Künstlerhaus KM-, Halle für Kunst \& Medien, s. d.

BOBIN, V. In the Fabric of the Voice: A Polyphonic Conversation, Manifesta Journal, n. 17, 2014. Retrieved from http://www.manifestajournal.org/issues/futures-cohabitation-0 (last accessed 06 June 2020).

BRASSIERE R. Mattin. http://www.mattin.org/essays/METAL_MACHINE_THEORY_3.html (last accessed 06 July 2020), s. d.

BULL, M. 2004. https://www.wired.com/2004/02/bull-session-with-professor-ipod/ (last accessed 06 June 2020).

CONNOR, S. In: Kelly, C. (ed.), SOUND: Documents of Contemporary Art, London: Whitechapel Gallery, Cambridge: The MIT Press, 2011.

DRESSLER, I. In: Christ Hans D., Dressler I., Peters C. (ed.), Acts of Voicing, The Poetics and Politics of the Voice, Leipzig: Spector Books, 2016.

GALlAUDET, E. M. American Annals of the Deaf, v. 26, 1881. Retrieved on http://saveourdeafschools.org/edward_miner_gallaudet_the_milan_convention.pdf (last accessed 06 July 2020).

GOODMAN, S. Sonic Warfare: Sound, Affect, and the Ecology of Fear. Cambridge and London: The MIT Press, 2012. 
HAINGE, G. Noise Matters: Towards an Ontology of Noise. New York/London: Bloomsbury, 2013.

HOSKOTE, R. In: Christ H. D., Dressler I., Peters C. (ed.). Acts of Voicing. Leipzig: Spector Books, 2014.

LAND, N. Fanged Noumena: Collected Writings 1987-2007. Windsor Quarry: Urbanomic and New York: Sequence Press, 2012.

MIGONE, C. Sonic Somatic: Performances of the Unsound Body. Los Angeles/Berlin: Errant Bodies Press, 2012.

MILLS, M., In: Novak, D. and Sakakeeny, M. (ed.). Keywords in Sound. Durham and London: Duke University Press, 2015.

NOVAK, D. In: Novak, D. and Sakakeeny, M. (ed.). Keywords in Sound. Durham and London: Duke University Press, 2015.

PRECIADO, P. B. (2015), https://www.internazionale.it/opinione/paulpreciado/2015/11/13/sessualita-disabili (last accessed 06 June 2020)

RANCIÈRE, J. In: CHRIST H. D., DRESSLER I., Peters C. (ed.). Acts of Voicing. Leipzig: Spector Books, [1999] 2014.

SCHAFER, M. In: KELLY, C. (ed.). SOUND: Documents of Contemporary Art. London: Whitechapel Gallery; Cambridge: The MIT Press, 2011.

SCHÖNHAMMER, R. The Walkman and the Primary World of the Senses, Phenomenology+Pedagogy, v. 7, p. 127-144, 1989. Retrieved from https://journals.library.ualberta.ca/pandp/index.php/pandp/issue/view/1059 (last accessed 06 June 2020).

SCHWARTZ, H. Making Noise: from Babel to the Big Bang and Beyond. Brooklyn, NY: Zone Books, 2011.

SERRES, M. The Parasite, Minneapolis: University of Minnesota Press, 2007.

SILENDA. Sonore, 2016. https://vimeo.com/191054577 (last accessed 06 June 2020)

STERNE, J. The Audible Past: Cultural Origins of Sound Reproduction, Durham and London: Duke University Press, 2003.

TABARELLA, F. I Cavatori, 1958. https:/www.youtube.com/watch?v=1-h5FR6IQ54 (last accessed 06 June 2020)

VOEGELIN, S. Listening to Noise and Silence: Towards a Philosophy of Sound Art. New York and London: Continuum, 2010.

ZDJELAR, K. In the Fabric of the Voice: A Polyphonic Conversation, Manifesta Journal, n. 17, 2014. Retrieved from http://www.manifestajournal.org/issues/futures-cohabitation-0 (last accessed 06 June 2020). 